Exercise Physiology

\title{
Acute whole-body electromyostimulation associated with dynamic exercises did not alter cardiac autonomic modulation and oxygen uptake in obese and eutrophic men
}

\author{
Gabriela Cassemiliano $^{1}$ (D), Paula Angélica Ricci ${ }^{1}$ (D), Soraia Pilon Jürgensen ${ }^{1}$ (D), \\ Bianca Cristina Domingos ${ }^{1}$ (D), Audrey Borghi-Silva ${ }^{1}$ \\ ${ }^{1}$ Universidade Federal de São Carlos, Laboratório de Fisioterapia Cardiopulmonar, São Carlos, \\ SP, Brazil.
}

Associate Editor: Katia de Angelis (D), Universidade Federal de São Paulo, São Paulo, SP, Brasil; ${ }^{2}$ Graduate Program in Translational Medicine, Universidade Nove de Julho, São Paulo, SP, Brazil. E-mail: prof.kangelis@yahoo.com.br.

\begin{abstract}
Aim: To contrast the acute effects of whole-body electromyostimulation (WB-EMS) with sham associated with dynamic exercises on cardiovascular, ventilatory, metabolic, and autonomic responses in men with obesity and controls. Methods: A randomized cross-over and double-blind trial with nine eutrophic (23.6 years; $23 \pm 1.4 \mathrm{~kg} / \mathrm{m}^{2}$ ) and ten men with obesity ( $26 \pm 4$ years; $38 \pm 7 \mathrm{~kg} / \mathrm{m}^{2}$ ), who were randomized to receive WB-EMS-Sham or Sham-WBEMS with $30 \mathrm{~min}$ of rest between protocols. WB-EMS protocol (Miha Bodytec $\AA$ ) was applied at the motor level, frequency $=85 \mathrm{~Hz}$, pulse duration $=350 \mu \mathrm{s}$, cycle on $=6^{\prime \prime}$; cycle off $=4^{\prime \prime}$. Sham group performed the same exercises with the electric current turned off. Throughout both protocols, subjects executed two dynamic exercises of 5 minutes each (step-up and step down associated with shoulder flexion, and lunge exercise associated with elbow flexion) in the same order. R-R intervals and breath-by-breath respiratory gases analysis were collected during the protocols. Heart rate variability (HRV) indexes were obtained using linear and nonlinear analysis. The level of statistical significance was set at $\mathrm{p}<0.05$. Results: Regarding both exercises, participants with obesity presented reduced oxygen uptake, higher ventilation, respiratory rate, blood pressure, and Borg scores $(\mathrm{p}<0.05)$ when contrasted with controls, as expected. However, no significant differences were found for HRV indexes between groups $(\mathrm{p}>0.05)$. In addition, WB-EMS did not increase oxygen uptake or altered autonomic modulation when contrasted with sham in both groups $(p<0.05)$. Conclusion: Obesity has a negative impact on symptoms and functional capacity. However, WB-EMS did not acutely enhance oxygen uptake or HRV during exercise in a population with obesity.
\end{abstract}

Keywords: obesity, whole-body electromyostimulation, heart rate variability, oxygen uptake, functional capacity.

\section{Introduction}

Obesity is associated with excessive accumulation of body fat, which has a multifactorial etiology, being attributed to genetic factors, imbalance in nutritional intake, and low energy expenditure ${ }^{1}$. In addition, obesity is related to several comorbidities, such as diabetes, hypertension, and cardiovascular diseases ${ }^{2}$. These comorbidities, alone or combined, contribute to promote impairments in cardiac autonomic control, producing altered adjustments during physical exercise ${ }^{3}$.

The treatment of obesity is still challenging, and new proposals for resources aimed at reducing excess weight are necessary. Dietary guidance and physical activity programs are the main pillars of conservative treatment ${ }^{4}$. In this context, physical exercise can increase energy expenditure and is typically included in the rehabilitation programs for the obesity population ${ }^{5,6}$. Also, physical exercise can beneficially modulate autonomic nervous control of chronic conditions ${ }^{7,8}$. However, due to a sedentary lifestyle behavior, the implementation of physical exercise programs becomes a great challenge in the population with obesity ${ }^{9}$. Furthermore, physical exertion, pain, and musculoskeletal comorbidities have been common exercise barriers ${ }^{10}$ in the population with obesity. For this reason, new training strategies including technologies that could facilitate exercise training programs and improve caloric expenditure could be promising resources ${ }^{11,12}$.

Neuromuscular electrical stimulation (NMES) can promote muscle strength gain when applied to the muscle that wants the action after three sessions ${ }^{13}$. Interestingly, when applied to more than one muscle group, whole-body electromyostimulation (WB-EMS) was able to increase oxygen uptake $\left(\dot{\mathrm{V}}_{2}\right)$ in patients with chronic heart fail- 
ure $^{14}$. Nonetheless, whether WB-EMS would improve $\dot{\mathrm{V}}_{2}$ in individuals with obesity remains unknown.

WB-EMS has been considered a promising technology due to its ability to stimulate up to 12 muscle groups simultaneously ${ }^{15}$. Associated with exercises, WB-EMS can also be effective in terms of time, enabling faster training $^{16}$ and considering the current lifestyle, which is one of the main causes of individuals abandoning physical exercise practice. Thus, new exercise strategies which require less time to be performed are becoming increasingly attractive to people seeking quality of life and health improvement. Moreover, WB-EMS associated with standard physical exercises can be an option to improve functional capacity in sedentary women ${ }^{17}$ and maybe a potentializing resource in improving autonomic adjustments during exercise and in the energy expenditure of population with obesity ${ }^{12}$. However, the short-term effects of WB-EMS on ventilatory, cardiovascular, autonomic, and perceptual responses following the dynamic exercises remain unclear in men with obesity when contrasted with controls.

The objectives of this study were: to contrast the acute effects WB-EMS with Sham associated with dynamic exercises on cardiovascular, ventilatory, metabolic, and autonomic responses in men with obesity and controls.

The main hypothesis tested in this study was that the group with obesity would present low responses during exercises and that WB-EMS may enhance autonomic and cardiorespiratory responses.

\section{Methods}

\section{Design and study population}

This was a randomized, cross-over, double-blind clinical study. All participants received clarification and guidance on the experimental procedures. This study was approved by the Human Research Ethics Committee of the Federal University of São Carlos (n 2960620) and included in the Brazilian Registry of Clinical Trials by the registry number RBR-3gzsnn. In addition, this study adhered to the Consolidated Standards for Reporting Trials (CONSORT $)^{18}$. All evaluations of the study were carried out at the Laboratory of our Institution.

Men aged between 18 and 40 years, with body mass index $(\mathrm{BMI})>30 \mathrm{~kg} / \mathrm{m}^{2}$ were considered participants with obesity, and men with BMI between 18.5 to $24.9 \mathrm{~kg} / \mathrm{m}^{2}$ were considered eutrophic. Men who used elicited drugs that influenced the autonomic nervous system, previous hypertensive, diabetes, or other cardiorespiratory and metabolic diseases were excluded from the present study. In addition, smokers, alcoholics, or users of medications that could alter the autonomic nervous system were also excluded.
The randomization of the participants (men with obesity and eutrophic) was performed in a 1: 1 block, with a difference in the order of the interventions $\left(1^{\circ}\right.$ : WBEMS and $2^{\circ}$ : Sham or $1^{\circ}$ : Sham and $2^{\circ}$ : WB-EMS, see in Figure 1). To perform this randomization, the website www.randomization.com was used.

All assessments took place at the same time of day to avoid different physiological responses due to circadian changes. Participants were instructed not to ingest caffeine, alcohol, or any other stimulant the night before and on the day of data collection, and not to perform strenuous activities the day before. All experiments were carried out with a controlled temperature between $22-24{ }^{\circ} \mathrm{C}$ and relative humidity between 40-60\%. All participants performed an anamnesis, physical activity level assessment, anthropometric assessment, cardiac autonomic modulation, metabolic and ventilatory analysis, in addition to previous familiarization with the equipment of WB-EMS.

\section{Experimental procedures}

Physical activity level assessment

The level of physical activity was assessed by information related to occupation, sports activities, and leisure habits through the questionnaire by Baecke ${ }^{19}$ which was validated and translated for adults ${ }^{20}$. This questionnaire consists of a scale from one to five (five representing the most active), with eight questions related to occupation, four addressing sports activities, and four addressing habitual leisure habits. The results were presented with the sum of the points (minimum score of five and maximum of fifteen).

\section{Anthropometric assessment}

The anthropometric assessment was performed based on the measurement of the participant's body mass and height, using a scale with a stadiometer (Welmy R110, Santa Barbara do Oeste, São Paulo, Brazil). In addition, participants were submitted to body composition assessment, using a digital scale (InBody 720, Biospace, Seoul, Korea). As standardized, the participants were instructed to attend in light clothing, with no metal in contact with the body, to urinate prior to the assessment, and not to perform strenuous physical activity the day before $^{21}$, and fast for at least four hours. The scale used contains analyzer electrodes that are in contact with the feet and the hands, capable of generating bioelectrical impedance through low tetrapolar electric current, thus it was possible to provide data on general body mass, lean mass, and fat mass. Afterward, participants had a light meal, so that fasting would not interfere in physical exercise $^{22}$.

\section{Collection of HR and RR intervals (RRi)}

Autonomic heart rate control was assessed non-invasively by analyzing and processing RRi and its variability. 


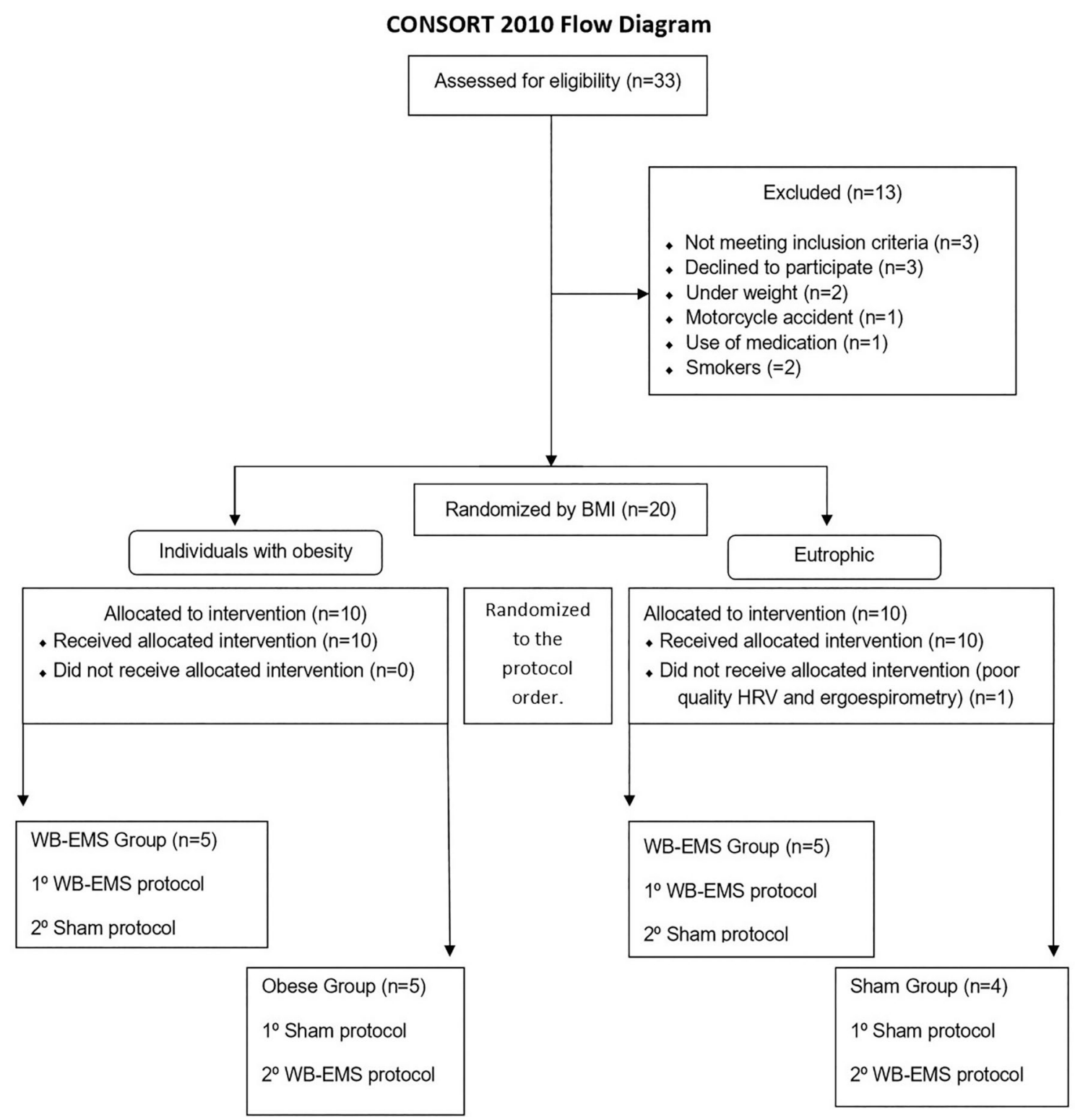

Figure 1 - Protocol of the exercise performed.

RRi was continuously obtained by a Polar S810i monitor (Polar Electro, Kempele, Oulu, Finland). This system is capable of detecting ventricular depolarization (corresponding to the $\mathrm{R}$ wave of the ECG) at a sampling rate of $500 \mathrm{~Hz}$. A transmitter band was attached to the participant's chest. The analysis was performed during the exercise of the two protocols performed.

\section{Pulmonary gas exchange and ventilatory measurements}

Analysis of the expired gases was performed during both exercise protocols. Participants breathed through a well-adjusted facial mask, which was connected to a breath-by-breath portable metabolic system (Oxycon Mobile®, Jäger, Wüzburg, Germany). The following data were recorded and exported to Excel® (Microsoft Excel,
2016): $\dot{\mathrm{V}} \mathrm{O}_{2},\left(\mathrm{~mL} \cdot \mathrm{kg}^{-1} \cdot \mathrm{min}^{-1}\right)$, carbon dioxide production $\left(\dot{\mathrm{V} C O}{ }_{2}, \mathrm{~mL} / \mathrm{min}\right)$; minute ventilation $\left(\dot{\mathrm{V}}_{\mathrm{E}}, \mathrm{L} / \mathrm{min}\right)$, respiratory rate (RR, rpm), and respiratory exchange ratio (RER). Additionally, the effort perception (dyspnea) and fatigue of the lower limbs were obtained using the Borg scale ${ }^{23}$, and systolic and diastolic blood pressure (BP) measurements were also collected at rest and the end of each exercise protocol.

The average of the total exercise time (ten minutes), which were processed in moving averages every fifteen seconds, was calculated in both protocols discarding the first fifteen seconds, including the initial third seconds of recovery (after the tenth minute). Moreover, a separate analysis of each exercise (step: from the 1st to the 5th minute and lunge exercise from the 5 th to the 10th minute) 
was also performed to observe the responses of each exercise.

\section{Whole-body electromyostimulation protocol (WB-EMS)}

The protocol was performed with a whole-body electrostimulator (MihaBodytec, Augsburg, Germany), which has a pair of shorts and a shirt, along with an adjustable waistcoat, a belt for the gluteal region, and bands for the upper and lower limbs that contains electrodes that transmit the electrical signal. Nevertheless, we have prioritized electromyostimulation only in the upper arms, upper legs, and gluteal region, as the electrodes on the chest could influence RRi collections, due to its positioning. In summary, the vest of the electrostimulator was only used to better suit the participant's clothing and because it is the central pole to interface the device with the electrodes of the limbs and gluteal region. The electrodes were wetted with water to perform proper electrical transmission to biological tissues so that the current stimulated the selected muscle groups simultaneously. In addition, the intensity was individually selected and coded during the session.

The exercise protocols consisted of two dynamic exercises: step-up and step down associated with shoulder flexion, and lunge exercise associated with elbow flexion simultaneously with WB-EMS or Sham. The individuals were instructed to perform the same number of exercises during the impulse duration (minimum of 3 , maximum of 4). WB-EMS parameters were Frequency $=85 \mathrm{~Hz}$; Pulse breadth $=350 \mu \mathrm{s}$; Impulse duration, $\mathrm{s}=6 \mathrm{~s}$; Impulse break, Time $=4 \mathrm{~s}$; Current Duration: ten minutes in each protocol. The first $5 \mathrm{~min}$ to go up and down the step, and the other $5 \mathrm{~min}$ to perform the lunge exercise, with 1-min more at the beginning, to introduce the electric current. The intensity used was considered moderate and intense during the WB-EMS protocol. During Sham protocol, no current was used. If there was sensory adaptation during the session, a physical therapist increased the current in the adapted muscle group.

The parameters of this protocol have been applied similarly before ${ }^{11,24}$. As in previous studies ${ }^{25,26}$, the intensity was considered when the participant felt the current at the motor level, and muscle contraction could be observed. In addition, a scale from 0 to 10 (Borg) was used to control the perceived intensity produced by the application of the WB-EMS, considering moderate and intense. Participants were instructed to signal us if there was any kind of pain, and the current was readjusted. Due to individual differences in sensitivity, the exact intensity of stimulation in milliamps has not been accurately described $^{27}$. After completing the first stage of electromyostimulation associated with physical exercise, the device was turned off and the participant remained for a 5min recovery period in the orthostatic position. Soon afterward, the electrodes and the ergospirometer were removed, and the participant remained with only the chestmounted Polar, to start the process of returning to baseline conditions again. After that, the participant stayed for $10 \mathrm{~min}$ of rest, and immediately after this period, the same exercise protocol was performed, but with the electric current turned off or vice versa.

\section{Data analysis}

For HRV analysis, the data were extracted and exported using the Polar ProTrainer program, through an interface, and then the most stable part of the signal that contained at least 256 points, which were calculated using the Kubios HRV software, was selected for visual inspection (MATLAB, version 2beta, Kuopio, Finland).

The data were analyzed using linear methodologies in the time and frequency domain, as well as non-linear methods ${ }^{28}$. In the time domain, the indices were calculated including the mean of the RRi, the mean of the HR, and root-mean-squared differences of successive $\mathrm{RRi}$ $(\mathrm{RMSSD}, \mathrm{ms})^{29}$. In the non-linear analysis, the Poincaré plot analysis of $\mathrm{SD}_{1}$ (instantaneous beat-to-beat variability) and $\mathrm{SD}_{2}$ (continuous beat-to-beat variability) were used $^{30}$. Then, the data were exported to the Excel® program for statistical analysis.

\section{Statistical analysis}

The data were analyzed using the SigmaPlot ${ }^{\circledR}$ statistical program (version 11.0, Systat Software Inc., São José, CA), and were expressed as mean or median (minimum, maximum), as appropriate, and confidence interval. The normality of the data was tested by the Shapiro-Wilk test.

The intergroup comparison for anthropometric variables was performed using the Student's $t$-test or MannWhitney, according to the nature of the data distribution, for the characterization data. Then, the Two-way ANOVA test with Tukey's post hoc was applied to assess the group (eutrophic men vs. men with obesity) and exercise protocols (WB-EMS vs. Sham) factors, as well as the interaction between them for the cardiorespiratory and metabolic variables and HRV. The level of statistical significance was set at $\mathrm{p}<0.05$. In addition, the effect sizes within each protocol (WB-EMS vs. Sham) were calculated using Cohen's $d$ were interpreted as trivial (0-0.19), small (0.20$0.49)$, medium $(0.50-0.79)$, or large $(\geq 0.80)^{31}$.

\section{Results}

A total of thirty-three participants were recruited, however, 13 participants were not eligible for the study; thus, twenty participants were divided into two groups according to their BMI. Ten men with obesity concluded the protocols, 5 of which were allocated to the sham-protocol first, performing the exercises with the device turned off, and the other 5 were allocated to the WB-EMS-proto- 
col, starting with the device on. One of the individuals in the eutrophic group was removed from the analysis for poor-quality HRV data, thus, nine eutrophic men concluded the study. In this group, 4 individuals started with Sham-protocol and 5 started with WB-EMS-protocol (see flowchart in Figure 2).

The general characteristics of the participants are shown in Table 1. Age, height, and level of physical activity did not differ between groups. As expected, significantly higher values of body mass, BMI, total fat mass, and total lean mass were observed in the men with obesity group when compared with the eutrophic group $(\mathrm{p}<0.05)$.
Table 2 shows HRV indexes obtained by linear and non-linear analysis during exercise protocols in both groups. The groups did not differ regarding HRV indexes and between the WB-EMS or Sham protocols $(\mathrm{p}>0.05)$.

The results of effect size calculations in the Sham protocol (Eutrophic vs. Obese) were: $\dot{\mathrm{O}}_{2}(\mathrm{~d}=2.08) ; \mathrm{V}_{\mathrm{E}}$ $(\mathrm{d}=0.98) ; \operatorname{RR}(\mathrm{d}=0.85) ; \mathrm{SBP}(\mathrm{d}=1.48)$; DBP $(\mathrm{d}=1.06)$, and dyspnea $(\mathrm{d}=0.67)$. For the WB-EMS protocol (Eutrophic vs. Obese) the results were: $\dot{\mathrm{VO}}_{2}(\mathrm{~d}=1.79)$; $\mathrm{V}_{\mathrm{E}}(\mathrm{d}=0.63)$; RR $(\mathrm{d}=0.51)$; SBP $(\mathrm{d}=1.35)$; DBP $(d=0.86)$, and dyspnea $(d=0.86)$.

Table 2 shows cardiorespiratory and metabolic variables during exercise in both groups. Participants with

\begin{tabular}{|l|l|l|l|l|l|}
\hline $5^{\prime}$ & $10^{\prime}\left(5^{\prime}\right.$ each exercise $)$ & $5^{\prime}$ & $5^{\prime}$ & $10^{\prime}\left(5^{\prime}\right.$ each exercise $)$ & $5^{\prime}$ \\
\hline
\end{tabular}

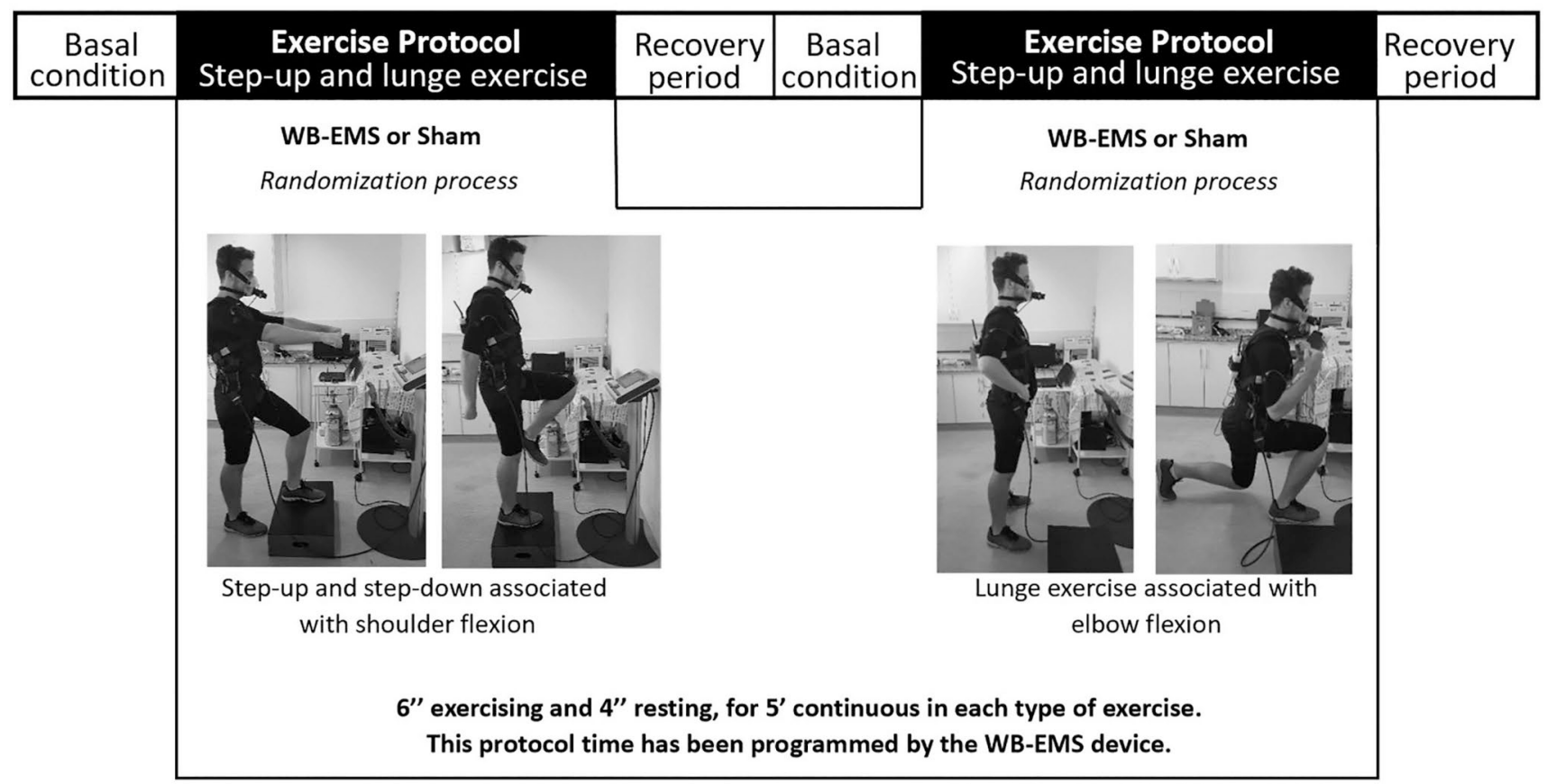

The participant authorized the use of his images.

Figure 2 - Flow diagram representing sample recruitment and loss.

Table 1 - Anthropometric, demographic, and body composition measurements.

\begin{tabular}{|c|c|c|c|}
\hline Variables & Eutrophic $(n=9)$ & Obese Group $(n=10)$ & p-value \\
\hline Age, years & $24(20-27)$ & $26(23-29)$ & 0.271 \\
\hline Body mass, kg & $73.7(67.6-79.7)$ & $121.6(109.4-133.8)$ & $<0.001$ \\
\hline Height, m & $1.79(1.74-1.84)$ & $1.80(1.75-1.84)$ & 0.749 \\
\hline BMI, $\mathrm{kg} / \mathrm{m}^{2}$ & $22.9(21.8-24.0)$ & $37.5(33.9-41.1)$ & $<0.001$ \\
\hline Body fat mass, $\mathrm{kg}$ & $11.1(8.4-13.8)$ & $46.9(37.5-56.4)$ & $<0.001$ \\
\hline Body lean mass, $\mathrm{kg}$ & $35.6(31.7-39.5)$ & $42.8(39.3-46.2)$ & 0.006 \\
\hline Baecke questionnaire & $7.1(6.5-7.7)$ & $6.6(6.0-7.1)$ & 0.151 \\
\hline
\end{tabular}

Data presented as mean and CI (confidence interval). BMI = body mass index. Teste t de Student. 


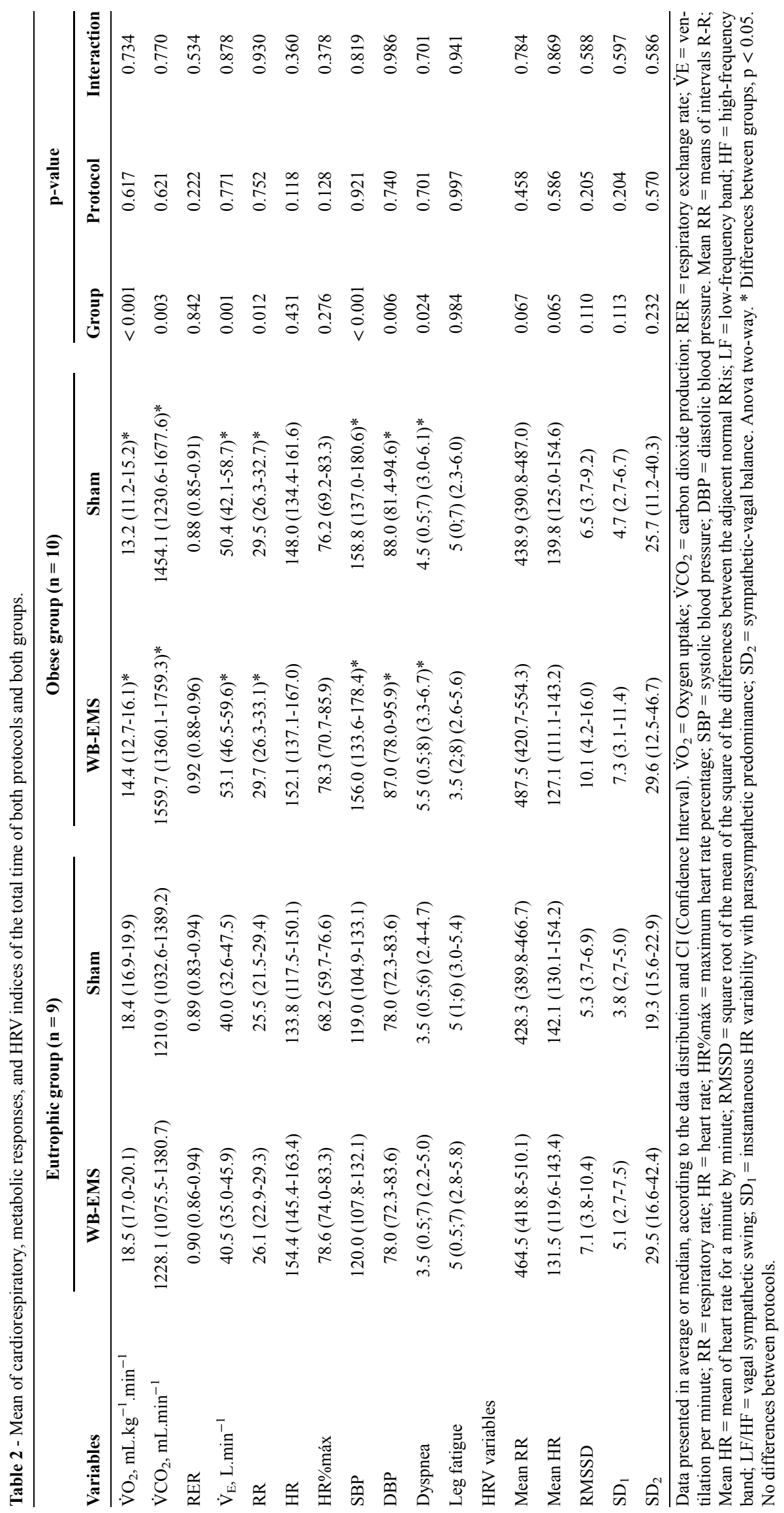


obesity had a lower $\dot{\mathrm{V}} \mathrm{O}_{2}$ and higher $\dot{\mathrm{V}} \mathrm{CO}_{2}, \dot{\mathrm{V}}_{\mathrm{E}}$ and RR when compared to controls, both in the Sham and WBEMS protocol. In addition, individuals with obesity also showed higher pressure responses as well as more symptoms of dyspnea in both exercise protocols applied (with or without WB-EMS) compared to eutrophic $(\mathrm{p}<0.05)$. However, there were no differences for $\mathrm{VO}_{2}$ or any other ventilatory, metabolic, or symptoms reported by individuals when comparing WB-EMS with Sham in both groups.

Table 3 shows the values of all variables in both groups, separated by each exercise period. As noted, there were no significant differences between the exercise protocols, nor the interaction between them. In the controls, practically all cardiopulmonary variables increased $(\mathrm{p}<0.05)$, except RR during the lunge exercise. Regarding the group with obesity, on the other hand, higher values were only observed in the variables $\dot{\mathrm{V}} \mathrm{CO}_{2}$, RER, and $\dot{\mathrm{V}}_{\mathrm{E}}$, during the exercise of lunge in both protocols WB-EMS and Sham $(\mathrm{p}<0.05)$.

\section{Discussion}

The present study aimed to verify the acute effects of a protocol with WB-EMS or Sham associated with dynamic exercises on cardiorespiratory, metabolic, and autonomic responses during a single session. Our findings demonstrated that obesity has a negative impact on symptoms and functional capacity. However, WB-EMS did not acutely enhance oxygen uptake or MAC during exercise in men with obesity. Lunge exercise increased energy expenditure in both groups when compared with step-up exercise. Therefore, these data, indicate that impaired cardiorespiratory, metabolic, and perceptual responses were not acutely affected by WB-EMS in men with obesity.

\section{Acute effects of WB-EMS on HRV indexes}

$\mathrm{HRV}$ analysis was performed during dynamic exercises, and it is not possible to observe significant differences when comparing the protocols, as well as the groups studied. A previous study has shown that electrical stimu-

Table 3 - Cardiopulmonary responses during Step up and Lunge exercise in both WB-EMS and Sham protocols.

\begin{tabular}{|c|c|c|c|c|c|c|c|}
\hline \multirow[b]{3}{*}{ Variables } & \multicolumn{7}{|c|}{ Eutrophic group } \\
\hline & \multicolumn{2}{|c|}{ Step up exercise } & \multicolumn{2}{|c|}{ Lunge exercise } & \multicolumn{3}{|c|}{ p-value } \\
\hline & WB-EMS & Sham & WB-EMS & Sham & Protocol & Exercise & Interaction \\
\hline$\dot{\mathrm{V}} \mathrm{O}_{2}, \mathrm{~mL} \cdot \mathrm{min}^{-1}$ & $1236.7(1025.6-1447.7)$ & $\begin{array}{c}1280.8 \\
(1120.8-1440.3)\end{array}$ & $\begin{array}{c}1446.5 \\
(1267.6-1625.5)\end{array}$ & $\begin{array}{c}1388.8 \\
(1234.3-1543.2)^{*}\end{array}$ & 0.928 & 0.047 & 0.513 \\
\hline$\dot{\mathrm{V}} \mathrm{O}_{2}, \mathrm{~mL} \cdot \mathrm{kg}^{-1} \cdot \mathrm{min}^{-1}$ & $17.0(15.1-18.9)$ & $17.6(16.0-19.1)$ & $19.8(18.3-21.3)^{*}$ & $19.1(17.5-20.6)$ & 0.905 & 0.005 & 0.389 \\
\hline$\dot{\mathrm{V}}_{2}, \%$ pred & $38.0(33.0-43.1)$ & $40.1(36.5-43.7)$ & $42.6(38.0-47.2)$ & $42.9(39.8-45.9)$ & 0.522 & 0.051 & 0.637 \\
\hline$\dot{\mathrm{V}} \mathrm{CO}_{2}, \mathrm{~mL} \cdot \mathrm{min}^{-1}$ & $969.5(814.4-1124.6)$ & $1004.3(871.1-1137.5)$ & $1439.5(1266.1-1612.9)^{*}$ & $\begin{array}{c}1381.9 \\
(1157.0-1606.7)^{*}\end{array}$ & 0.881 & $<0.001$ & 0.546 \\
\hline RER & $0.78(0.74-0.81)$ & $0.78(0.74-0.81)$ & $0.94(0.94-1.03)^{*}$ & $0.98(0.91-1.06)^{*}$ & 0.912 & $<0.001$ & 0.770 \\
\hline $\mathrm{V}_{\mathrm{E}}, \mathrm{L} \cdot \mathrm{min}^{-1}$ & $32.2(27.0-37.5)$ & $33.7(28.2-39.3)$ & $47.2(40.7-53.7)^{*}$ & $45.2(35.8-54.7)^{*}$ & 0.940 & $<0.001$ & 0.563 \\
\hline \multirow[t]{3}{*}{ RR } & $24.0(22.1-26.0)$ & $24.6(20.6-28.6)$ & $26.8(23.5-30.2)$ & $26.2(22.2-30.2)$ & 0.969 & 0.150 & 0.683 \\
\hline & \multicolumn{7}{|c|}{ Obese group } \\
\hline & \multicolumn{2}{|c|}{ Step up exercise } & \multicolumn{2}{|c|}{ Lunge exercise } & \multicolumn{3}{|c|}{ p-value } \\
\hline Variables & WB-EMS & Sham & WB-EMS & Sham & Protocol & Exercise & Interaction \\
\hline$\dot{\mathrm{V}} \mathrm{O}_{2}, \mathrm{~mL} \cdot \mathrm{min}^{-1}$ & $1544.3(1290.5-1798.2)$ & $1527.4(1250.9-1803.8)$ & $1732.1(1470.7-1993.5)$ & $\begin{array}{c}1646.6 \\
(1360.4-1932.7)\end{array}$ & 0.794 & 0.146 & 0.907 \\
\hline$\dot{\mathrm{V}} \mathrm{O}_{2}, \mathrm{~mL} \cdot \mathrm{kg}^{-1} \cdot \mathrm{min}^{-1}$ & $13.0(11.0-15.0)$ & $12.6(10.5-14.7)$ & $14.4(12.2-16.6)$ & $14.0(11.6-16.4)$ & 0.710 & 0.122 & 0.936 \\
\hline$\dot{\mathrm{VO}}_{2}, \%$ pred & $43.1(36.4-49.7)$ & $43.0(34.6-51.4)$ & $49.5(44.0-55.0)$ & $46.2(38.0-54.3)$ & 0.596 & 0.142 & 0.613 \\
\hline$\dot{\mathrm{V} C O}{ }_{2}, \mathrm{~mL} \cdot \mathrm{min}^{-1}$ & $1232.0(1051.6-1412.4)$ & $1240.2(998.8-1481.5)$ & $1752.9(1489.9-2016.0)^{*}$ & $\begin{array}{c}1629.4 \\
(1331.3-1927.4)^{*}\end{array}$ & 0.687 & $<0.001$ & 0.632 \\
\hline RER & $0.82(0.77-0.86)$ & $0.80(0.76-0.85)$ & $1.01(0.95-1.06)^{*}$ & $0.97(0.93-1.01)^{*}$ & 0.141 & $<0.001$ & 0.445 \\
\hline$\dot{\mathrm{V}}_{\mathrm{E}}, \mathrm{L} \cdot \mathrm{min}^{-1}$ & $42.9(36.9-49.0)$ & $44.1(34.9-53.2)$ & $58.8(50.1-67.5)^{*}$ & $55.7(45.2-66.3)^{*}$ & 0.894 & $<0.001$ & 0.666 \\
\hline $\mathrm{RR}$ & $29.9(26.5-32.7)$ & $29.6(26.5-32.7)$ & $29.6(26.5-32.7)$ & $29.9(26.0-33.8)$ & 0.929 & 0.928 & 0.891 \\
\hline
\end{tabular}

Data presented in mean and confidence interval $(\mathrm{CI})$. $\dot{\mathrm{V}} \mathrm{O}_{2}=$ Oxygen uptake; $\dot{\mathrm{VCO}}_{2}=$ carbon dioxide production; $\mathrm{RER}=$ respiratory exchange rate; $\dot{\mathrm{V}}_{\mathrm{E}}=$ ventilation per minute; $\mathrm{RR}=$ respiratory rate. ANOVA two way. ${ }^{*}$ Differences between Exercises, $\mathrm{p}<0.05$ No differences between protocols. 
lation can modulate the sympathetic and parasympathetic activity of nerves ${ }^{30}$. However, other authors have demonstrated that electrostimulation in muscles of vastus lateralis and vastus medialis was not able to acutely affect HRV in healthy individuals ${ }^{32}$. In the present study, participants received NMES in more muscle groups in addition to performing an associated dynamic exercise protocol. Nonetheless, no differences in autonomic modulation indexes when contrasted with the Sham condition were observed.

It is known that individuals with obesity have changes in cardiac autonomic function and sympathetic hyperactivity due to excess fat, which results in increased heart rate. In addition, other factors, such as hormonal changes in obesity, are also factors involved in autonomic dysfunction $^{33}$. Despite this, there is no evidence from studies evaluating the HRV response during an acute WB-EMS protocol. A recent study by our group ${ }^{12}$ applied a protocol of WB-EMS associated with dynamic exercises for 6 weeks in patients with morbid obesity after bariatric surgery. Chronically, WB-EMS did not promote additional improvements of HRV indices either. Regarding acute intervention, our findings also indicate no additive effect of WB-EMS, both in men with obesity group and controls.

\section{Acute effects of WB-EMS on cardiorespiratory, metabolic} variables and physical effort symptoms

Obesity has the potential to affect several factors during exercise, and the accumulation of body fat negatively affects the function of the respiratory system ${ }^{34}$. Studies show that individuals with obesity usually have impaired gas exchange, disorders of lung function, and depressed exercise capacity, contributing to greater dyspnea, being the most prevalent symptom in this population $^{35}$. It is well defined in the literature that people with obesity have reduced oxygen consumption for a given activity and, consequently, there may be an increase in the variables of $\dot{\mathrm{VCO}}_{2}$ and $\dot{\mathrm{V}}_{\mathrm{E}}$, when compared to controls in the same workload ${ }^{36}$.

Di Thommazo-Luporini et al. ${ }^{35}$ compared the functional capacity of eutrophic women and women with obesity through the cardiopulmonary test, and lower values of $\dot{\mathrm{V}} \mathrm{O}_{2}$ in participants with obesity and higher values of SBP in both exercise protocols were shown. The same characteristic was observed by another study ${ }^{37}$ when comparing men with obesity with controls, obtaining lower values of $\dot{\mathrm{V}}_{2}$ and higher values of blood pressure in individuals with obesity, when submitted to cardiopulmonary testing.

A protocol composed of WB-EMS has been proven to be an interesting methodology to be used in populations with exercise intolerance ${ }^{16}$. In a recent study, D'Ottavio et al. ${ }^{38}$ suggest that WB-EMS associated with resistance and strength exercises, in a 6-week intervention, increased the feeling of effort regardless of the population participating in the training. In this sense, this technique with different long-term exercises can be beneficial in the rehabilitation process, for individuals with obesity and eutrophic ones, with different goals.

A few studies examined the variations in metabolic and cardiovascular behavior during a session with WBEMS in different populations. A previous study evaluated the energy expenditure in a protocol with WB-EMS during the training of low-intensity resistance exercises, simultaneously stimulating the upper legs, upper arms, gluteus, abdomen, chest, and back, in individuals moderately trained ${ }^{11}$. They observed that the energy expenditure was higher with WB-EMS when compared with controls (exercise only). Bearing this in mind, it is worth mentioning that, according to the Baecke questionnaire, individuals were sedentary in our study. Moreover, the exercises were performed with stimulation only in the upper arms, upper legs, and gluteus, which may explain our findings.

\section{Physical exercises associated with the whole-body electromyostimulation (WB-EMS) protocol}

Dynamic physical exercise is performed by large muscle groups, with a displacement of a considerable part, or all, of body mass. Thus, the increase of oxygen uptake and carbon dioxide production during dynamic exercise requires complex adjustments in the cardiovascular and respiratory systems ${ }^{35}$. In this way, we observed higher values in the $\dot{\mathrm{V}} \mathrm{O}_{2}, \dot{\mathrm{V} C O} \mathrm{O}_{2}, \mathrm{RER}$, and $\dot{\mathrm{V}}_{\mathrm{E}}$ in the lunge exercise, when compared with the step-up exercise for controls, while for participants with obesity only in variables $\dot{\mathrm{V}} \mathrm{CO}_{2}, \mathrm{RER}$, and $\dot{\mathrm{V}}_{\mathrm{E}}$ for the same exercise. Though, no additional acute effect was observed on cardiorespiratory and metabolic responses with WB-EMS.

Several authors have carried out different intervention protocols composed of exercises associated with the WB-EMS, as shown by the systematic review by Kemmler and collaborators ${ }^{39}$, in order to improve health aspects in different populations. Nevertheless, to our knowledge, there are no studies that have evaluated the acute effects of a single session of WB-EMS on people with obesity.

In our study, we observed greater cardiorespiratory and metabolic responses during lunge exercise when compared to step-up, both in the sham groups and in the participants with obesity. Information regarding caloric expenditure linked to the execution of the lunge exercise is still not known in the literature; However, Lagally and collaborators ${ }^{40}$ compared a weight training protocol with functional training, which involved lunge exercise in healthy adults, and concluded that functional training caused higher oxygen consumption and energy expenditure. Yet, further studies are needed in order to investigate the effects of lunge exercise individually, in eutrophic and people with obesity. 


\section{Limitations of the study}

First, we consider it important to analyze HR and HRV with a good signal during exercise protocols, using the band on the individuals' chest, and for this reason, this prevented us from using electrical stimulation in the chest, abdomen, and back, and this may have influenced our results. Moreover, our study did not include other populations and has a small sample size, however, we believe that it was possible to observe unprecedented results with this protocol.

We concluded that obesity has a negative impact on symptoms and functional capacity. Besides, WB-EMS did not enhance the effects of physical exercises on cardiac autonomic modulation, cardiopulmonary and metabolic responses of men with obesity or eutrophic men. Lunge exercise led to greater ventilatory and metabolic demand in both groups, being an alternative for weight loss programs. Further studies focusing on long-term intervention programs with the use of WB-EMS, with a larger sample and other populations, should be carried out in the future.

\section{Practical applications}

The concern with the treatment of obesity has grown recently, and because it is considered a multifactorial disease, its treatment is still quite challenging, and new proposals for resources aimed at reducing obesity and comorbidities are necessary. In an attempt to expand the possibilities of intervention programs for this population, WB-EMS has demonstrated several long-term benefits in several populations, including individuals with obesity. However, WB-EMS has been gaining prominence in the scientific environment and the media since it promises to burn up to $500 \mathrm{kcal}$ in a single session. Our findings provide solid evidence that $\mathrm{O}_{2}$ consumption does not change sharply, as well as cardiac autonomic control, is similar when compared to the Sham situation. Future studies should be carried out to evaluate, by calorimetry, the burning of fat right after the exercise session.

\section{Conflict of interest}

The authors declare that they do not have any financial relationship with the commercial identities or associative interests that represents a potential conflict of interest in connection with the present study.

\section{Acknowledgments}

The authors are grateful for the participation of all the research volunteers. The authors thank all colleagues from Cardiopulmonary Physical Therapy Laboratory for their collaboration, and the volunteers of this research for their effort and enthusiastic cooperation throughout the study. This research was funded by a grant from "Fundação de
Amparo à Pesquisa do Estado de São Paulo" (FAPESP) 2015/04101-1; 2017/22895-0; 2018/13332-5 and CAPES 001. ABS is an Established Investigator (level IB) of the Conselho Nacional de Desenvolvimento Científico e Tecnológico (CNPq), Brazil.

\section{References}

1. Poddar M, Chetty Y, Chetty VT. How does obesity affect the endocrine system? A narrative review. Clin Obes. 2017;7(3):136-44. doi

2. Scherer PE, Hill JA. Obesity, diabetes, and cardiovascular diseases. Circ Res. 2016;118(11):1703-5. doi

3. Carvalho LP, Di Thommazo-Luporini L, Mendes RG, Cabiddu R, Ricci PA, Basso-Vanelli RP, et al. Autonomic neuroscience: basic and clinical metabolic syndrome impact on cardiac autonomic modulation and exercise capacity in obese adults. Auton Neurosci Basic Clin. 2018;213:43-50. doi

4. Bray GA, Frühbeck G, Ryan DH, Wilding JPH. Management of obesity. Lancet. 2016;387(10031):1947-56. doi

5. Drenowatz C, Hand GA, Shook RP, Jakicic JM, Hebert JR, Burgess $\mathrm{S}$, et al. The association between different types of exercise and energy expenditure in young non-overweight and overweight adults. Appl Physiol Nutr Metab. 2015;40 (3):211-17.doi.

6. Verreijen AM, Engberink MF, Memelink RG, Van der Plas SE, Visser M, Weijs PJM. Effect of a high protein diet and/ or resistance exercise on the preservation of fat-free mass during weight loss in overweight and obese older adults: a randomized controlled trial. Nutr J. 2017;16(1):1-8. doi

7. Borghi-Silva A, Mendes RG, Trimer R, Fregonezi GA, Resqueti VR, Arena R, et al. Potential effect of 6 versus 12weeks of physical training on cardiac autonomic function and exercise capacity in chronic obstructive pulmonary disease. Eur J Phys Rehabil Med (Europa Medicophysica). 2015;51(2):211-21.

8. Castello-Simões V, Polaquini Simões R, Beltrame T, Bassi $\mathrm{D}$, Catai AM, Arena R, et al. Effects of aerobic exercise training on variability and heart rate kinetic during submaximal exercise after gastric bypass surgery - a randomized controlled trial. Disabil Rehabil. 2013;35:334-42. doi

9. Marshall SJ, Ramirez E. Reducing sedentary behavior: a new paradigm in physical activity promotion. Am J Lifestyle Med. 2011;5(6):518-30. doi

10. Joseph PL, Bonsignore A, Kunkel GF, Grace SL, Sockalingam S, Oh P. Benefits and barriers to exercise among individuals with class III obesity. Am J Health Behav. 2019;43(6):1136-47. doi

11. Kemmler WO, von Stengel S, Schwarz J, Mayhew J. Effect of whole-body electromyostimulation on energy expenditure during exercise. J Strength Cond Res. 2012;26(1):2405. doi.

12. Ricci PA, Di Thommazo-Luporini L, Jürgensen SP, André LD, Haddad GF, Arena R, et al. Effects of whole-body electromyostimulation associated with dynamic exercise on functional capacity and heart rate variability after bariatric surgery: a randomized, double-blind, and sham-controlled trial. Obes Surg. 2020;30(10):3862-71. doi. 
13. Laufer Y, Ries JD, Leininger PM, Alon G. Quadriceps femoris muscle torques and fatigue generated by neuromuscular electrical stimulation with three different waveforms. Phys Ther. 2001;81(7):1307-16. doi

14. Casillas JM, Gremeaux V, Labrunee M, Troigos O, Laurent Y, Deley G, et al. Low-frequency electromyostimulation and chronic heart failure. Ann Readapt Med Phys. 2008;51 (6):461-72. doi

15. Kemmler W, Froehlich M, Kleinõder H. Whole-body electromyostimulation - the need for common sense! Rationale and guideline for a safe and effective training. Dtsch Z Sportmed. 2016;67(9):218-20. doi

16. Pano-Rodriguez A, Beltran-Garrido JV, Hernández-González V, Reverter-Masia J. Effects of whole-body electromyostimulation on health and performance: A systematic review. BMC Complement Altern Med. 2019;19(1):1-14. doi

17. Kemmler W, Schliffka R, Mayhew JL, von Stengel S. Effects of whole-body electromyostimulation on resisting metabolic rate, body composition, and maximum strength in postmenopausal women: the training and electroStimulation trial. J strength Cond Res. 2010;(40):1880-7.

18. Schulz KF, Altman DG, Moher D, CONSORT Group. CONSORT 2010 Statement: updated guidelines for reporting parallel group randomised trials. BMC Medicine. 2010;7(3):e1000251. doi

19. Baecke JAH, Burema J, Frijters JER. A short questionnaire for the measurement of habitual physical activity in epidemiological studies. Am J Clin Nutr. 1982;36(5):936-42. doi

20. Florindo AA, Latorre MRD. Validação e reprodutibilidade do questionário de Baecke de avaliação da atividade física habitual em homens adultos. Rev Bras Med do Esporte. 2003;9(3):129-35.

21. Kyle UG, Bosaeus I, De Lorenzo AD, Deurenberg P, Elia M, Gómez JM, et al. Bioelectrical impedance analysis-part II: utilization in clinical practice. Clin Nutr. 2004;23 (6):1430-53. doi

22. Ling CHY, de Craen AJM, Slagboom PE, Gunn DA, Stokkel MPM, Westendorp RGJ, et al. Accuracy of direct segmental multi-frequency bioimpedance analysis in the assessment of total body and segmental body composition in the middle-aged adult population. Clin Nutr. 2011;30 (5):610-15. doi.

23. Borg GA. Psychophysical bases of perceived exertion. Med Sci Sports Exerc. 1982;14(5):377-81.

24. Teschler M, Wassermann A, Weissenfels A, Fröhlich M, Kohl M, Bebenek M, et al. Short time effect of a single session of intense whole-body electromyostimulation on energy expenditure. A contribution to fat reduction? Appl Physiol Nutr Metab. 2018;43(5):528-30. doi

25. André LD, Basso-Vanelli RP, Ricci PA, Di ThommazoLuporini L, de Oliveira CR, Haddad GF, et al. Whole-body electrical stimulation as a strategy to improve functional capacity and preserver lean mass after bariatric surgery: a randomized triple-blind controlled trial. Int $\mathrm{J}$ Obes. 2021;45:1476-87. doi

26. Kemmler W, Kleinöder H, Fröhlich M. Editorial. Wholebody electromyostimulation: a training technology to improve health and performance in humans? Front Physiol. 2020;11:523. doi

27. Berger J, Becker S, Backfisch M, Eifler C, Kemmler W, Fröhlich M. Adjustment effects of maximum intensity tolerance during whole-body electromyostimulation training. Front Physiol. 2019;10:1-7. doi

28. Camm A, Malik M, Bigger J, Breithardt G, Cerutti S, Cohen $\mathrm{R}$, et al. Guidelines heart rate variability. Eur Heart J. 1996;17:354-81. doi

29. Vanderlei LCM, Pastre CM, Hoshi A, Dias T, Fernandes M. Noções básicas de variabilidade da frequência cardíaca e sua aplicabilidade clínica. Rev Bras Cir Cardiovasc. 2009;24(2):205-17. doi.

30. Stein C, Lago PD, Ferreira JB, Casali KR, Della R, Plentz $\mathrm{M}$. Autonomic neuroscience : basic and clinical transcutaneous electrical nerve stimulation at different frequencies on heart rate variability in healthy subjects. Auton Neurosci Basic Clin. 2011;165(2):205-8. doi

31. Cohen JA.Power Primer. Psychol Bull. 2011;112(1):155-9. doi

32. Kang JH, Hyong IH. The influence of neuromuscular electrical stimulation on the heart rate variability in healthy subjects. J Phys Ther Sci. 2014;26(5):633-5. doi

33. Schwartz MW, Seeley RJ, Zeltser LM, Drewnowski A, Ravussin E, Redman LM, et al. Obesity pathogenesis: an endocrine society scientific statement. Endocr Rev. 2017;38 (4):267-96. doi

34. Mafort TT, Rufino R, Costa CH, Lopes AJ. Obesity: systemic and pulmonary complications, biochemical abnormalities, and impairment of lung function. Multidiscip Respir Med. 2016;11(1):28. doi

35. Di Thommazo-Luporini L, Jürgensen SP, Castello-Simões V, Catai AM, Arena R, Borghi-Silva A. Metabolic and clinical comparative analysis of treadmill six-minute walking test and cardiopulmonary exercise testing in obese and eutrophic women. Brazilian J Phys Ther. 2012;16(6):46978. doi

36. Di Thommazo-Luporini L, Carvalho LP, Luporini RL, Trimer R, Pantoni CBF, Martinez AF, et al. Are cardiovascular and metabolic responses to field walking tests interchangeable and obesity-dependent? Disabil Rehabil. 2016;38 (18):1820-9. doi

37. Carvalho LP, Di Thommazo-Luporini L, Aubertin-Leheudre M, Junior JCB, Zangrando KTL, Trimer R, et al. Prediction of cardiorespiratory fitness by the six-minute step test and its association with muscle strength and power in sedentary obese and lean young women: a cross-sectional study. PLoS One. 2015;10(12):e0145960. doi

38. D'Ottavio S, Briotti G, Rosazza C, Partipilo F, Silvestri A, Calabrese C, et al. Effects of two modalities of whole-body electrostimulation programs and resistance circuit training on strength and power. Int J Sports Med. 2019;40(13):83141. doi

39. Kemmler W, Weissenfels A, Willert S, Shojaa M, von Stengel S, Filipovic A, et al. Efficacy and safety of low-frequency whole-body electromyostimulation (WB-EMS) to improve health-related outcomes in non-athletic adults. A systematic review. Front Physiol. 2018;9(573):1-12. doi. 
40. Lagally KM, Cordero J, Good J, Brown DD, McCaw ST. Physiologic and metabolic responses to a continuous functional resistance exercise workout. J Strength Cond Res. 2009;23(2):373-9. doi.

\section{Corresponding author}

Audrey Borghi-Silva. Universidade Federal de São Carlos, Laboratório de Fisioterapia Cardiopulmonar, Rod. Washington Luis, km 235, 13565-905, São Carlos, SP,

Brazil.

E-mail: audrey@ufscar.br
Manuscript received on May 17, 2021

Manuscript accepted on October 2, 2021

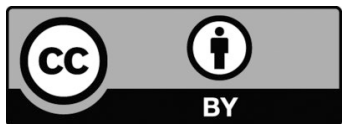

Motriz. The Journal of Physical Education. UNESP. Rio Claro, SP, Brazil - eISSN: 1980-6574 - under a license Creative Commons - Version 4.0 